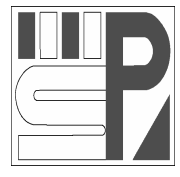

Science Press
Journal of Arid Land

2012, 4(3): 231-240

doi: 10.3724/SP.J.1227.2012.00231

jal.xjegi.com; www.chinasciencejournal.com

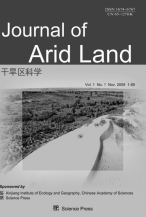

\title{
Pleniglacial millennium-scale climate variations in northern China based on records from the Salawusu River Valley
}

\author{
FengNian WANG ${ }^{1}$, BaoSheng $\mathrm{LI}^{1,2 *}$, JiangLong WANG ${ }^{3}$, XiaoHao WEN ${ }^{1}$, DongFeng NIU ${ }^{1}$, ZhiWen $\mathrm{LI}^{4}$, \\ YueJun $\mathrm{SI}^{1}$, YiHua GUO ${ }^{1}$, ShuHuan $\mathrm{DU}^{5}$ \\ ${ }^{1}$ School of Geography, South China Normal University, Guangzhou 510631, China; \\ ${ }^{2}$ State Key Laboratory of Loess and Quaternary Geology, Institute of Earth Environment, Chinese Academy of Sciences, \\ Xi'an 710061, China; \\ ${ }^{3}$ Chenghai Middle School, Shantou 510601, China; \\ ${ }^{4}$ College of Earth Science, East China Institute of Technology, Nanchang 330013, China; \\ ${ }^{5}$ Key Laboratory of Marginal Sea Geology, South China Sea Institute of Oceanology, Chinese Academy of Sciences, \\ Guangzhou 510301, China
}

\begin{abstract}
Situated in the Salawusu River Valley, southeast of China's Mu Us Desert, the MGS2 (Milanggouwan section) portion of the Milanggouwan stratigraphic section records 5.5 sedimentary cycles consisting of alternations between dune sand deposits and fluvial or lacustrine facies. We analyzed the grain-size and $\mathrm{CaCO}_{3}$ distributions in MGS2, and found that $\mathrm{Mz}$ (mean particle diameter) and $\sigma$ (standard deviation) displayed clear variations in peaks and valleys within different sedimentary facies. The $\mathrm{CaCO}_{3}$ content averaged $0.4 \%$ in the dune sand deposits, $1.43 \%$ in the fluvial facies, and $8.82 \%$ in the lacustrine facies. Both the grain-size distribution and $\mathrm{CaCO}_{3}$ contents, which equal the indicators for the alternation among the sedimentary facies, suggest the occurrence of 5.5 cycles. These results suggest that the observed cycles mainly resulted from fluctuations between a cold and dry winter monsoon climate and a warm and humid summer monsoon climate, and that the MGS2 portion experienced at least 5.5 fluctuations between these two extremes. This high-frequency climatic fluctuation indicates a strong influence of millennium-scale variations in the strength of the East Asian winter and summer monsoons in our study area during the Pleniglacial.
\end{abstract}

Keywords: Salawusu River Valley; Pleniglacial; paleoclimatic indices; $\mathrm{CaCO}_{3}$; grain-size

The global climate has experienced dramatic changes since the Last Glacial period, especially from the Pleniglacial to the Postglacial periods. A series of rapid, high-frequency climate variations occurred in the North Atlantic (perhaps even globally) during this period. Many researchers (e.g. Dansgaard et al., 1989, 1993; Grootes et al., 1993) found evidence of Dansgaard-Oeschger $(\mathrm{D} / \mathrm{O})$ oscillations during the Last Glacial in the Greenland ice cores. Bond et al. (1992, 1993) and Bond and Lotti (1995) found evidence of 13 ice-raft debris events between $38 \mathrm{ka} \mathrm{BP}$ and $10 \mathrm{ka} \mathrm{BP}$ in the North Atlantic. Heinrich $(\mathrm{H})$ and Younger
Dryas (YD) events were also recorded in low-latitude deep-sea sediments (Broecker, 1994; Thompson et al., 1995), loess deposits (Xiao et al., 1995; Sun et al., 1996; An, 2000; Liu et al., 2011), lake sediments (Wang et al., 2005; Luo et al., 2008), deserts (Ding et al., 1996; Li et al., 2010; Shao et al., 2010), and stalagmites (Wang et al., 2001). The Chinese loess and ice core deposits (Yao and Shi, 1992) particularly recorded millennium-scale climate fluctuations from 35 $\mathrm{ka}$ BP to $15 \mathrm{ka}$ BP in China. All of these findings

Received 2012-01-12; accepted 2012-04-19

"Corresponding author: BaoSheng LI (E-mail: libsh@scnu.edu.cn) 
improved our understanding of the global climate variations and monsoon changes since the last glaciation. However, climate change on the Ordos Plateau during this period remains poorly understood. To provide more information in this regard, we studied a sedimentary deposit, the Milanggouwan section, to find clues to the climate change in this region of China.

\section{Study area and methods}

Located on the southeastern margin of China's Mu Us
Desert, the Ordos Plateau (Fig. 1), the Salawusu River Valley provided abundant geological information on environmental variations during the Late Quaternary. Since the late 1970s, researchers have made great progress in understanding the evolution of the Late Quaternary environment (Yuan, 1978; Dong et al., 1983; Li et al., 2000, 2005; Jin et al., 2007; Huang et al., 2009). In recent years, some researchers have reported that the MGS2 portion of the Milanggouwan stratigraphic section in the Salawusu River Valley, which is synchronous to MIS2 in the North Atlantic, consists of dune sands alternating with fluvial or

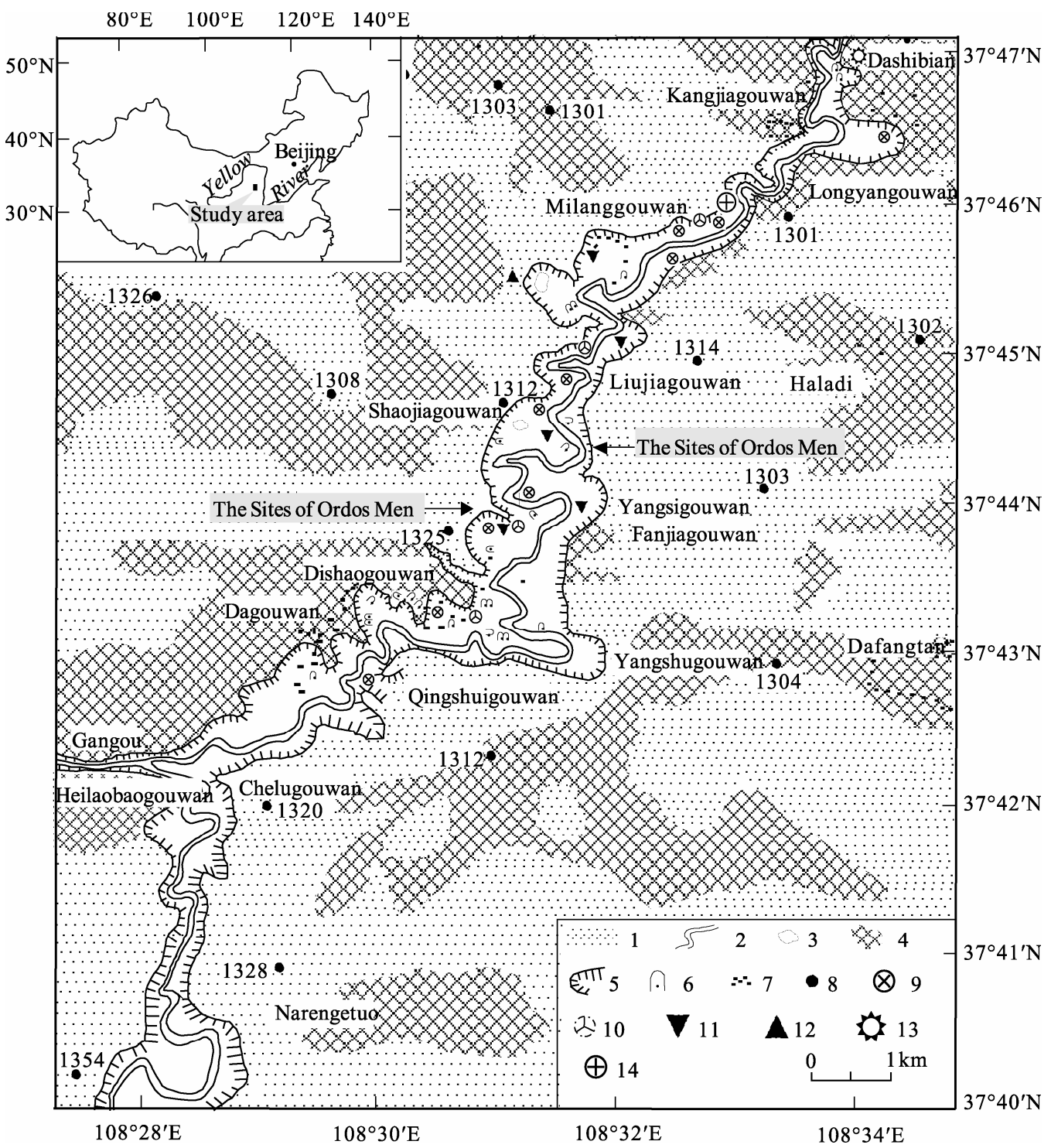

Fig. 1 The location of the Salawusu River and the study area

Note: 1, Mu Us Desert; 2, the Salawusu River; 3, lakes or ponds; 4, the plateau surface, which is composed of black soil or lacustrine facies; 5, cliff; 6, cave; 7, residential site; 8, height above sea level; 9 , exposed site of fossil vertebrates; 10, exposed site with human fossils and artefacts; 11, exposed site of paleolithic implements; 12, exposed site of neolithic implements; 13 , ancient city site; 14 , location of the Milanggouwan section 
lacustrine facies, and therefore represents obvious sedimentary cycles ( $\mathrm{Li}$ et al., 2000, 2007; Li et al., 2010). Moreover, these cycles correspond well to the climate variations preserved in records from continental ice cores (Yao and Shi, 1992). By determining the ages and analyzing the grain-size characteristics and $\mathrm{CaCO}_{3}$ contents of MGS2, and in combination with proxy paleoclimatic indices based on fossil data, we analyzed the climate variations that occurred in this part of China during the Pleniglacial.

\subsection{MGS2 strata sequence}

The MGS2 segment of the Milanggouwan section is situated along the left bank of the Salawusu River at the middle reaches, about $500 \mathrm{~m}$ northeast of Milanggouwan village $\left(108^{\circ} 33^{\prime} 05.4^{\prime \prime} \mathrm{E}, 37^{\circ} 45^{\prime} 47.2^{\prime \prime N}\right.$; Fig. 1). The profile is $1,290 \mathrm{~m}$ above sea level, and the sediment thickness is about $83 \mathrm{~m}$. The MGS2 is a series of continuous sedimentary sequences with depths ranging from 8.76 to $13.63 \mathrm{~m}$ (Fig. 2), including a total of 11 overlapping layers from 20D to 30D: six layers containing aeolian paleo-mobile dune sands (20D, 22D, 24D, 26D, 28D, 30D), three layers containing fluvial facies (21FL, 23FL, 29FL) and two layers con- taining lacustrine facies (25LS, 27LS). For the convenience of our study, we have labeled the paleo-mobile dune sands, fluvial facies, and lacustrine facies in the sedimentary cycles using D, FL, and LS, respectively.

The paleo-mobile dune sands mainly consist of fine sands, followed by medium and very fine sands. These sediments are grey-yellow, loosely compacted, and evenly sorted, with occasional aeolian beddings. The fluvial facies also mainly consist of fine sands, followed by moderately coarse and very fine sands, and are grey-yellow, but they have a higher silt content and contain obvious fluvial beddings and calcareous deposits at the bottom, with occasional congeliturbated folds in some layers. The lacustrine facies are bluegrey, silty fine sands, with a higher clay content and clear congeliturbated folds.

\subsection{Ages of the layers of MGS2}

We dated five horizons from the MGS2 segment and its adjacent areas by means of radiocarbon $\left({ }^{14} \mathrm{C}\right)$ and thermoluminescence (TL) dating, for a total of two ${ }^{14} \mathrm{C}$ dates and three TL dates (Li et al., 2010) (Fig. 2). The ${ }^{14} \mathrm{C}$ determination was performed using a low-back

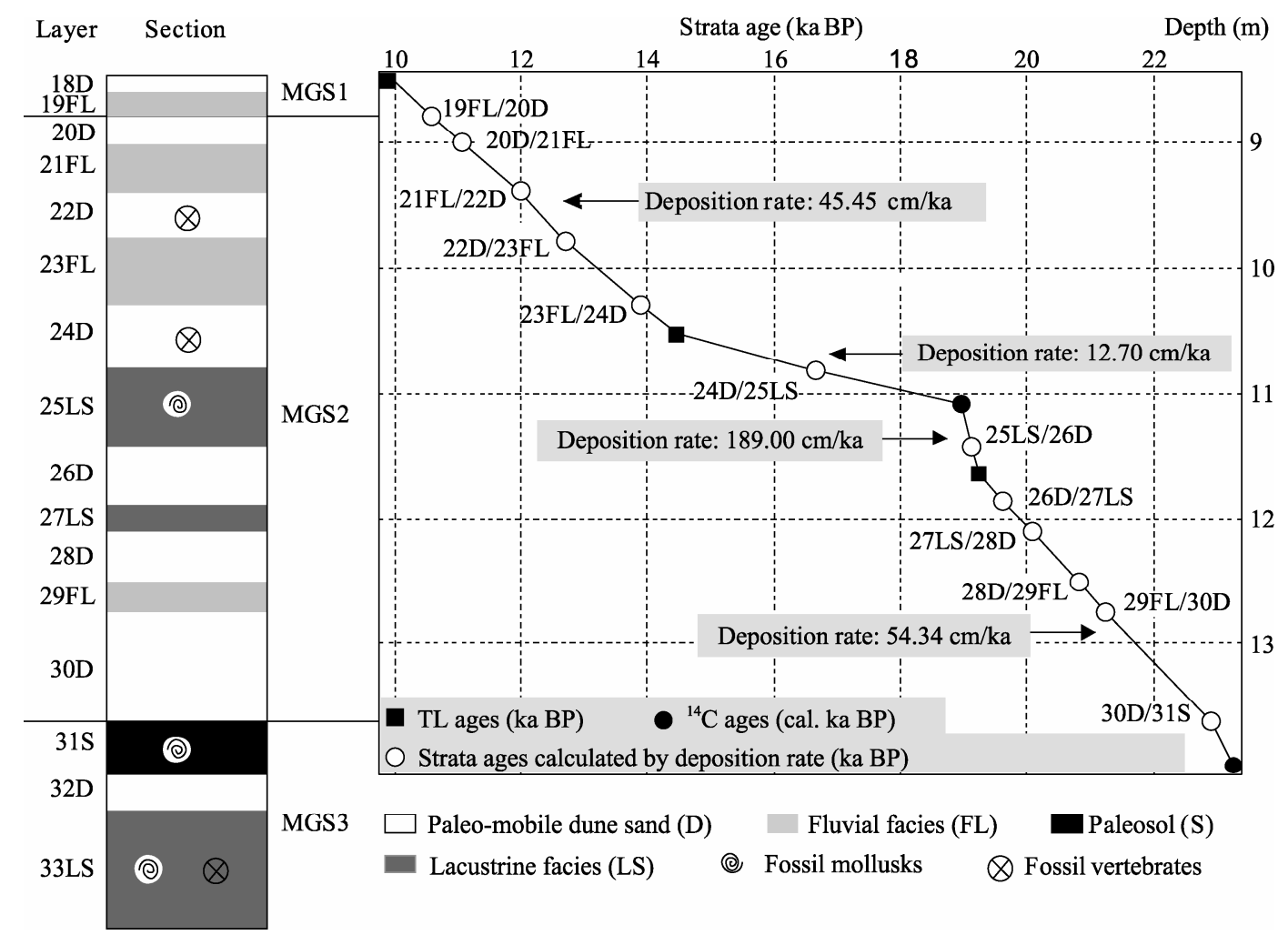

Fig. 2 The sedimentary sequences and ages in the MGS2 portion of the Milanggouwan section 
ground-value liquid scintillation counter (Beijing Nuclear Instrument Corporation, Beijing, China) at the ${ }^{14} \mathrm{C}$ lab of the Cold and Arid Regions Environmental and Engineering Research Institute, Chinese Academy of Sciences, Lanzhou, China. The ${ }^{14} \mathrm{C}$ dating materials from the middle of $25 \mathrm{LS}$ and $31 \mathrm{~S}$ were shells of fossil mollusks and soil organic matter, and the dated ages were $15.611 \pm 0.219$ and $19.57 \pm 0.366$ ka BP, respectively. The calibrated ages, determined using the Calib501 software (Stuiver et al., 1998), were $18.945 \pm 0.382$ and $23.266 \pm 0.597$ cal. ka BP, respectively.

For the top of $18 \mathrm{D}$ and the middle of $26 \mathrm{D}$, the TL analyses were performed using a Type 711 age determination instrument (Littlemore Scientific Instrument Corporation, Oxford, UK) in the TL lab of the Guangzhou Institute of Geochemistry, Chinese Academy of Sciences, Guangzhou, China. For the middle of $24 \mathrm{D}$, the TL analyses were performed using a Type 7185 age determination instrument (Littlemore Scientific Instrument Corporation) in the TL lab of Beijing University, China. The TL dating materials for the top of $18 \mathrm{D}$ and for the middle of 24D and 26D were quartz grains smaller than $10 \mu \mathrm{m}$. For the top of $18 \mathrm{D}$ and the middle of $26 \mathrm{D}$, the dated ages were $9.880 \pm 0.900$ and $19.236 \pm 1.554$ ka BP, respectively. For the middle of $24 \mathrm{D}$, the dated age was $14.458 \pm 0.867 \mathrm{ka}$ BP. TL ages and the relevant parameters are listed in Table 1.

In Fig. 2, the top of MGS2 is at the interface between 19FL and 20D. Based on the ages of 18D $(9.880 \pm 0.90 \mathrm{TL} \mathrm{ka} \mathrm{BP})$ and $24 \mathrm{D}(14.458 \pm 0.867 \mathrm{TL}$ $\mathrm{ka} \mathrm{BP})$, and the sedimentary rate $(45.45 \mathrm{~cm} / \mathrm{ka})$ from $18 \mathrm{D}$ to $24 \mathrm{D}$, we calculated that the age of the top of MGS2 is $10.58 \mathrm{ka} \mathrm{BP}$. Similarly, the bottom of MGS2 is at the interface between 30D and 31S. Based on the ages of $26 \mathrm{D}(19.236 \pm 1.554 \mathrm{TL} \mathrm{ka} \mathrm{BP})$ and $31 \mathrm{~S}$ (23.266 $\pm 0.597 \mathrm{cal}$. ka BP), and the sedimentary rate $(54.34 \mathrm{~cm} / \mathrm{ka})$ from $26 \mathrm{D}$ to $31 \mathrm{~S}$, we calculated that the age of the bottom of MGS2 is $22.89 \mathrm{ka} \mathrm{BP}$. Table 2 summarizes the estimated ages of the 11 layers in MGS2. Based on these results, the period covered by MGS2 ranged from about 23 ka BP to about $11 \mathrm{ka}$ BP.

\subsection{Methods}

We collected a total of 98 samples at an average interval of $5 \mathrm{~cm}$ (some at intervals of 3 or $6 \mathrm{~cm}$ ) in the MGS2 portion of the Milanggouwan section. Of these, 57 samples were of paleo-mobile dune sands, 24 samples were of fluvial facies, and 17 samples were of lacustrine facies. We analyzed the grain-size and $\mathrm{CaCO}_{3}$ for all the samples.

The grain-size distribution was analyzed with a mastersizer 2000M analyzer (Malvern Instruments, Malvern, UK), which has a measurement range of 0.02 to $2,000 \mu \mathrm{m}$. The experimental procedure was based on the method used for grain-size analysis of loess deposits ( $\mathrm{Lu}$ and An, 1997). We repeated the determination three times for each sample, and used the average value in subsequent analyses.

All grain-size data were stored in a database and the values of various parameters were calculated by using the MatLab 7.0 software.

Table 1 TL dating results for three layers in the Milanggouwan section and relevant parameters

\begin{tabular}{cccccccc}
\hline Layer/number & Depth $(\mathrm{m})$ & $\mathrm{U}(\mathrm{ppm})$ & $\mathrm{Th}(\mathrm{ppm})$ & $\mathrm{K}(\%)$ & Annual dose $(\mathrm{mGy})$ & Total dose $(\mathrm{Gy})$ & $\mathrm{TL}(\mathrm{ka} \mathrm{BP})$ \\
\hline 18D/TGD-627 & 8.440 & $0.920 \pm 0.050$ & $6.070 \pm 0.120$ & $1.910 \pm 0.015$ & $2.480 \pm 0.080$ & $186.200 \pm 13.960$ & $9.880 \pm 0.900$ \\
24D/PKG586 & 10.525 & 1.834 & 8.514 & 1.140 & 2.652 & $33.562 \pm 4.774$ & $14.458 \pm 0.867$ \\
26D/XAL895 & 11.645 & 5.500 & 4.100 & 1.700 & 3.160 & $60.806 \pm 3.210$ & $19.236 \pm 1.554$ \\
\hline
\end{tabular}

Table 2 The ages of the dated dune (D), fluvial (FL), and lacustrine (LS) layers in MGS2

\begin{tabular}{cccccc}
\hline Layer & Depth $(\mathrm{m})$ & Ages $(\mathrm{ka} \mathrm{BP})$ & Layer & Depth $(\mathrm{m})$ & Ages $(\mathrm{ka} \mathrm{BP})$ \\
\hline 20D & $8.99-8.76$ & $11.09-10.58$ & $21 \mathrm{FL}$ & $9.39-8.99$ & $11.97-11.09$ \\
22D & $9.74-9.39$ & $12.63-11.97$ & $23 \mathrm{FL}$ & $10.27-9.74$ & $13.90-12.63$ \\
24D & $10.78-10.27$ & $16.47-13.90$ & $25 \mathrm{LS}$ & $11.41-10.78$ & $19.11-16.47$ \\
26D & $11.88-11.41$ & $19.67-19.11$ & $27 \mathrm{LS}$ & $12.10-11.88$ & $20.07-19.67$ \\
28D & $12.50-12.10$ & $20.81-20.07$ & $29 \mathrm{FL}$ & $12.74-12.50$ & $21.25-20.81$ \\
30D & $13.63-12.74$ & $22.89-21.25$ & & & \\
\hline
\end{tabular}


The $\mathrm{CaCO}_{3}$ analysis was performed using a Bascomb calcimeter, and each sample was tested 3 to 4 times (Bascomb, 1961). First, we weighed a known quantity of each sample, then mixed it with excess $\mathrm{HCl}$ and recorded the reaction-generated volume and temperature of $\mathrm{CO}_{2}$. Based on the equation $P V=n \mathrm{R} T$ (where $P$ is pressure, $V$ volume, $n$ the molar quantity of $\mathrm{CO}_{2}$ produced, $\mathrm{R}$ the ideal gas constant, and $T$ the temperature $(\mathrm{K})$ ), we calculated the carbonate contents from the amount of $\mathrm{CO}_{2}$ :

$$
\begin{gathered}
n=P V / \mathrm{RT}, \\
\mathrm{CaCO}_{3} \text { content }=\mathrm{CO}_{2} \text { content } \times(100 / 44) .
\end{gathered}
$$

\section{Results}

\subsection{Grain-size}

Based on the grain-size results, we found that the dune sands (57 samples) were mostly sandy deposits, consisted of fine sands $(70.7 \%$ by mass), followed by medium sands (14.8\%) and very fine sands $(12.8 \%)$, with very low silt and clay contents. The fluvial facies (24 samples) were similar to the dune sands in deposit composition, but with a lower content of fine sands $(59.8 \%)$, a higher content of very fine sands $(24.9 \%)$, and a slightly lower content of medium sands $(10.5 \%)$; the silt content was much higher $(4.7 \%)$, but the clay content remained low. In the lacustrine facies (17 samples), the fine sand was dominant (40.9\%), followed by silt $(26.0 \%)$ and very fine sands $(22.4 \%)$; the content of medium sands decreased greatly (to $5.1 \%$ ), and the clay content increased greatly (to $5.6 \%$ ). We also summarized the grain-size composition of different layers in MGS2 in Table 3.

If the values of $\mathrm{Mz}$ and $\sigma$ are taken to represent the grain-size features for the sedimentary facies (Folk and Ward, 1957), the characteristics are more obvious. The $\mathrm{Mz}$ and $\sigma$ of the dune sands ranged from 2.10 to 3.02 and from 0.45 to 0.92 , respectively, and averaged 2.48 and 0.61 , respectively. The $\mathrm{Mz}$ and $\sigma$ of the fluvial facies ranged from 2.36 to 3.03 and from 0.52 to 0.93 , respectively, and averaged 2.75 and 0.76 , respectively. The $\mathrm{Mz}$ and $\sigma$ of the lacustrine facies ranged from 2.75 to 4.44 and from 0.77 to 2.02 , respectively, and averaged 3.71 and 1.58 , respectively. These results show that the dune sands were relatively coarse and evenly sorted, whereas the fluvial and lacustrine facies were relatively fine and poorly sorted. The changes in grain size from coarse in the dune sands to fine in the overlying fluvial or lacustrine facies reveal 5.5 cycles (from 20D to 30D) that change from coarse grains to fine grains. The values of $\mathrm{Mz}$ and $\sigma$ show alternations in peaks and valleys between layers in MGS2, and both appear to have nearly the same variation trends, which are similar to the results shown by the sedimentary cycles (Fig. 3).

\section{$2.2 \mathrm{CaCO}_{3}$}

Figure 4 summarizes the range of $\mathrm{CaCO}_{3}$ contents in MGS2. Based on these results, we can discern the following characteristics of MGS2:

(1) $\mathrm{CaCO}_{3}$ contents differed greatly among the layers, ranging from 0 to $15.6 \%(\mathrm{w} / \mathrm{w})$ and averaging $2.1 \%$. Figure 3 shows considerable oscillation in the $\mathrm{CaCO}_{3}$ values over time.

\begin{tabular}{|c|c|c|c|c|c|c|c|}
\hline Layer & Coarse sand & Medium sand & Fine sand & $\begin{array}{l}\text { Very fine sand } \\
\qquad(\%)\end{array}$ & Coarse silt & Fine silt & Clay \\
\hline $20 \mathrm{D}$ & 0.00 & 17.30 & 77.45 & 5.00 & 0.25 & 0.00 & 0.00 \\
\hline $21 \mathrm{FL}$ & 0.00 & 7.16 & 59.74 & 28.64 & 4.33 & 0.09 & 0.04 \\
\hline $22 \mathrm{D}$ & 0.19 & 21.66 & 57.99 & 16.22 & 3.81 & 0.08 & 0.03 \\
\hline $23 \mathrm{FL}$ & 0.03 & 15.44 & 55.92 & 22.91 & 5.55 & 0.11 & 0.04 \\
\hline $24 \mathrm{D}$ & 0.08 & 19.50 & 57.73 & 17.68 & 4.86 & 0.10 & 0.08 \\
\hline $25 \mathrm{LS}$ & 0.00 & 3.95 & 35.39 & 21.75 & 26.61 & 5.11 & 7.20 \\
\hline $26 \mathrm{D}$ & 0.00 & 10.63 & 74.30 & 14.24 & 0.83 & 0.00 & 0.00 \\
\hline $27 \mathrm{LS}$ & 0.00 & 8.89 & 58.80 & 24.65 & 7.00 & 0.32 & 0.36 \\
\hline $28 \mathrm{D}$ & 0.00 & 20.79 & 73.03 & 6.12 & 0.08 & 0.00 & 0.00 \\
\hline $29 \mathrm{FL}$ & 0.00 & 5.14 & 68.56 & 23.16 & 2.97 & 0.07 & 0.10 \\
\hline $30 \mathrm{D}$ & 0.00 & 8.14 & 78.04 & 13.28 & 0.28 & 0.04 & 0.20 \\
\hline
\end{tabular}

Table 3 Average grain-size composition in different layers of MGS2 

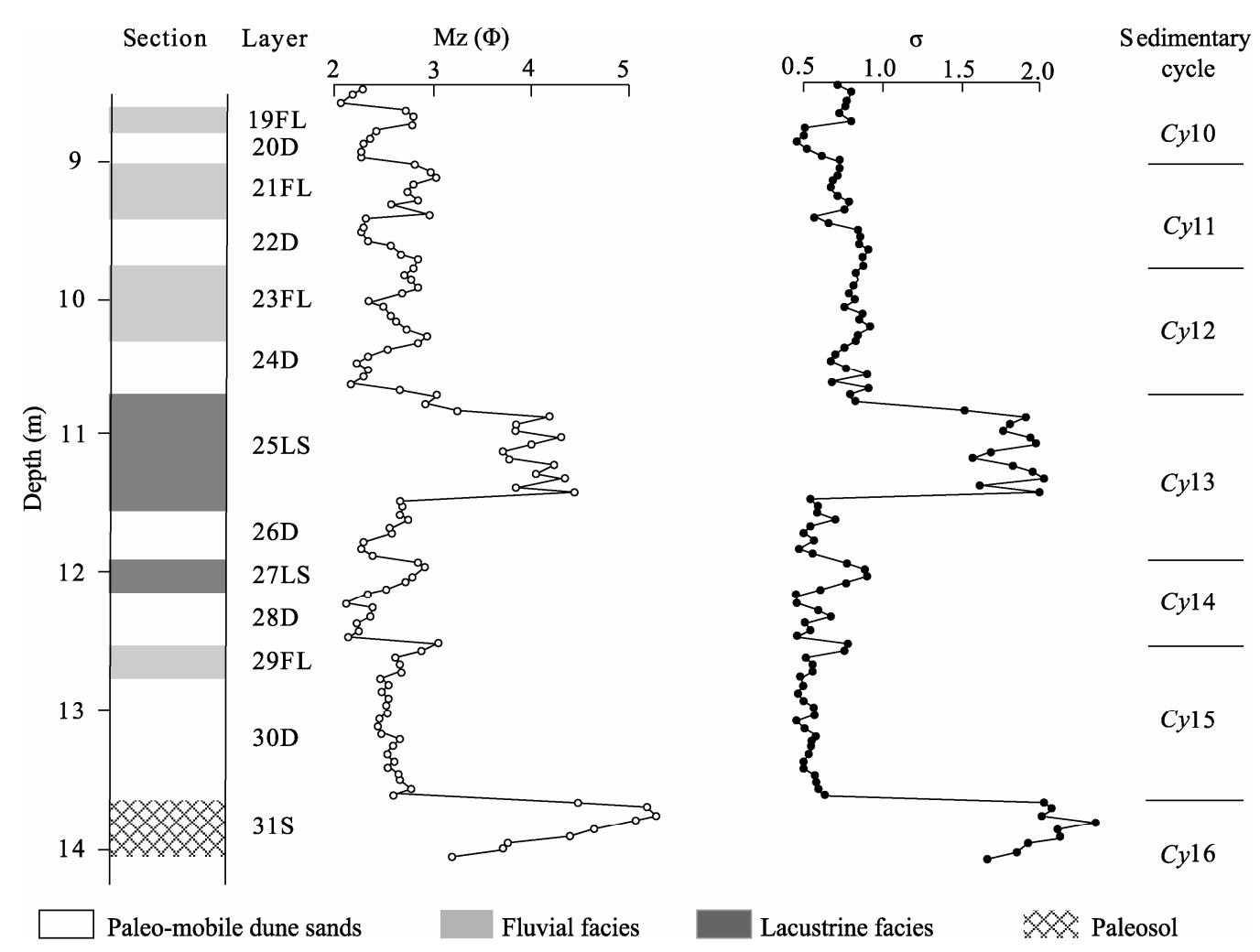

Fig. 3 Variations in grain-size parameters $\mathrm{Mz}$ and $\sigma$ in MGS2

(2) There were obvious differences in the $\mathrm{CaCO}_{3}$ contents among the different sedimentary facies. In the dune sands, the $\mathrm{CaCO}_{3}$ contents ranged from 0 to $2.9 \%$ and averaged $0.4 \%$. In the fluvial facies, they ranged from $0.1 \%$ to $2.6 \%$ and averaged $1.4 \%$. In the lacustrine facies, they ranged from $0.4 \%$ to $15.6 \%$ and averaged $8.8 \%$.

(3) $\mathrm{The} \mathrm{CaCO}_{3}$ contents revealed certain trends in the different lithofacies, with lower values in dune sands but peak values in overlying fluvial or lacustrine facies. $\mathrm{CaCO}_{3}$ also appeared to follow the sedimentary cycles. The 5.5 cycles (from 20D to 30D) shown by the $\mathrm{CaCO}_{3}$ contents appeared to follow the alternation between dune sands and the overlying fluvial or lacustrine facies.

\section{$2.3 \mathrm{Mz}(\Phi)$ and $\mathrm{CaCO}_{3}(\%)$}

To further explore the relationships between the $\mathrm{CaCO}_{3}$ contents and the grain-size characteristics of the sedimentary facies, we graphed the $\mathrm{CaCO}_{3}$ values as a function of $\mathrm{Mz}$ with a significant correlation $r=0.89$ (Fig. 5). In general, the data for each sedimentary facies were relatively concentrated, the pa- leo-mobile dune sands and fluvial facies grouped near the origin, with their $\mathrm{CaCO}_{3}$ contents largely overlapping but with a smaller $\mathrm{Mz}$ value for the dune sands, whereas the lacustrine facies had a wider range of values, but mostly had a combination of high $\mathrm{CaCO}_{3}$ and high $\mathrm{Mz}$. The paleo-mobile dune sands mainly had $\mathrm{CaCO}_{3}<1.0 \%$ and $\mathrm{Mz}$ from 2.10 to 3.00. The fluvial facies mainly had $\mathrm{CaCO}_{3}$ contents ranging from $1.0 \%$ to $2.5 \%$ and $\mathrm{Mz}$ ranging from 2.25 to 3.00 . The lacustrine facies mainly had $\mathrm{CaCO}_{3}>3.0 \%$ and $\mathrm{Mz}$ from 3.25 to 4.50 . Based on these data, we regard $\mathrm{Mz}$ 2.25 vs. $\mathrm{CaCO}_{3} \quad 1.00 \%$ as the boundary between paleo-mobile dune sands and the other two facies.

\section{Results}

A recent analysis of modern dune sands in the Mu Us Desert showed that the ranges of values for $\mathrm{Mz}$ (1.94 to 3.39 , averaged 2.76$)$ and $\sigma(0.35$ to 1.03 , averaged 0.58) (Du et al., 2009) were similar to those for the paleo-mobile dune sands in MGS2. The $\mathrm{CaCO}_{3}$ contents of modern dune sands ranged from 0 to $2.8 \%$ and averaged $0.6 \%$, which is similar to the values for the 
paleo-mobile dune sands in MGS2. These similarities suggest that the sedimentation environments of the two scenarios are similar, both dominated by the in- fluence of the winter monsoon with a prevailing cold and dry climate and strong winds (An, 2000). In the periods when the summer monsoon prevailed, inflows

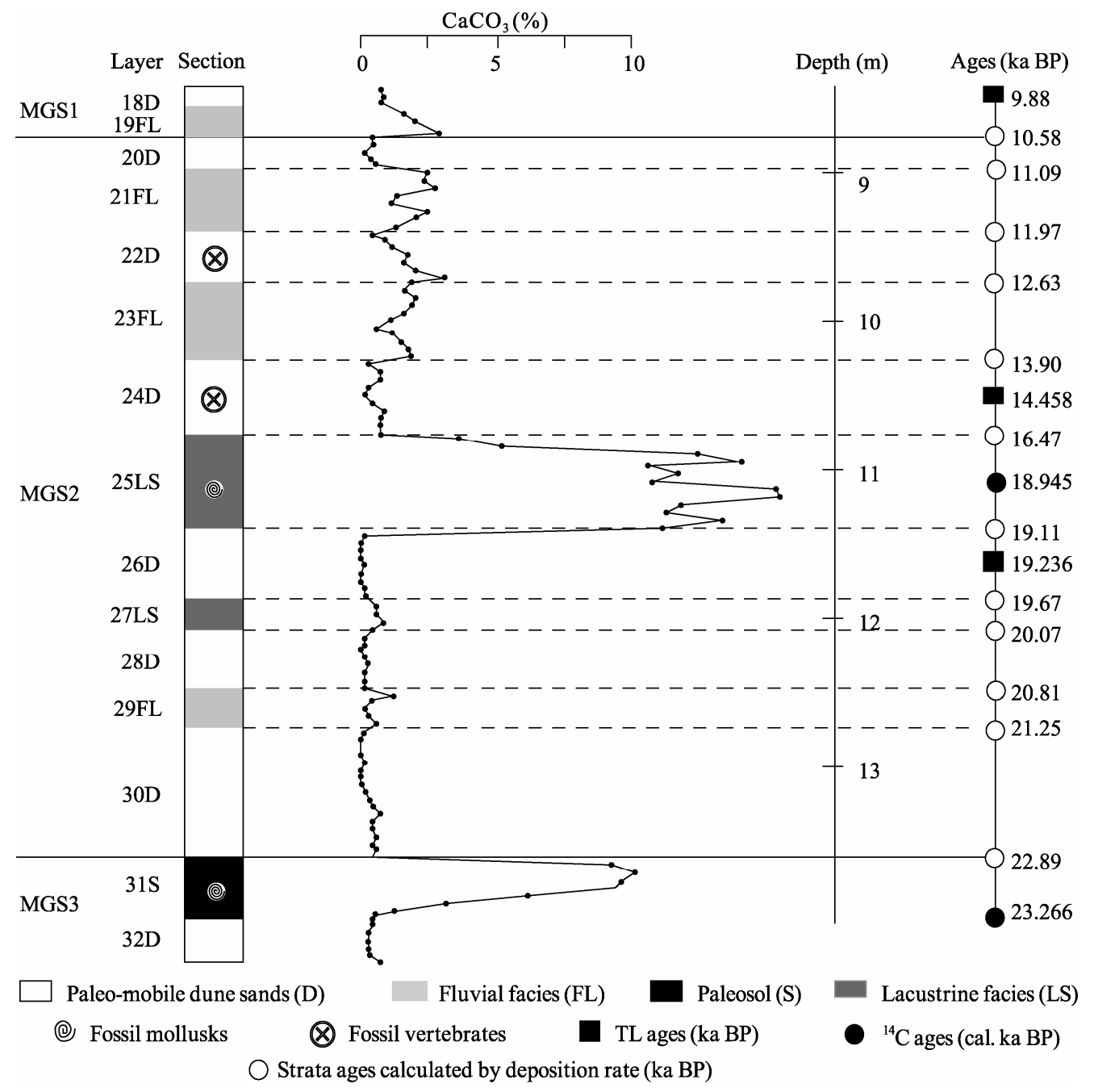

Fig. 4 Variations in $\mathrm{CaCO}_{3}$ contents in MGS2

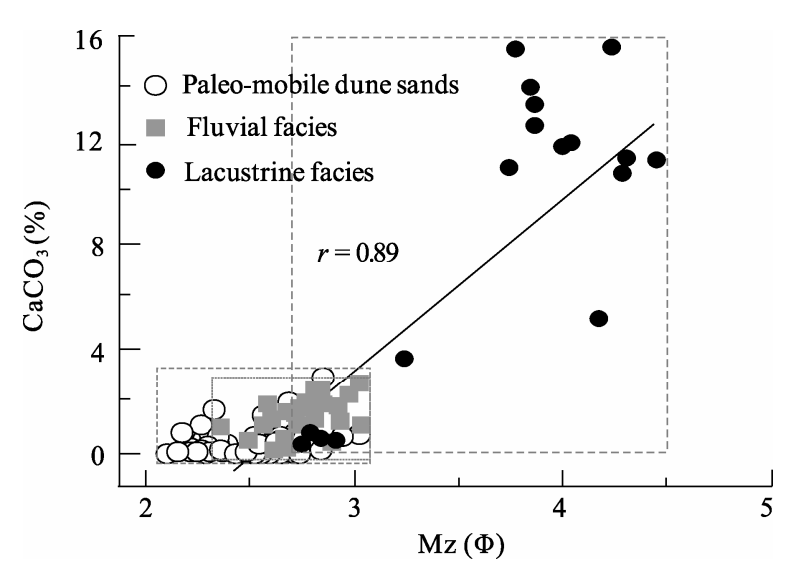

Fig. 5 The relationships between mean grain sizes $(\mathrm{Mz})$ and $\mathrm{CaCO}_{3}$ contents in the three groups of sedimentary facies in MGS2 of warm and humid air masses from the ocean weakened the dominance of the winter monsoon and the high wind speeds that previously led to the accumulation of dune sands weakened; the increased precipitation caused the expansion of rivers and lakes, and fluvial and lacustrine facies developed. As a result, the contents of coarse grains in the fluvial and lacustrine facies decreased and the Mz values increased. In addition, biochemical weathering increased (Li et al., 2007) during periods dominated by the summer monsoon, increasing the proportion of fine particles, which were carried into rivers and lakes by flowing water, thereby increasing the fine sand and clay contents in the flu- 
vial and lacustrine facies of MGS2.

The dune sands of MGS2 are obviously the results of a strong wind regime, which is typical of the winter monsoon. This suggests that when the winter monsoon began strengthening during the Pleniglacial, the weather was cold and dry and the region around our study area was likely affected by strong winds that led to sand accumulation. During this period, the $\mathrm{CaCO}_{3}$ in the dune sand sediments would be produced by mechanical erosion and affected by transportation and accumulation processes, but because of the low temperatures and precipitation, chemical weathering would have been slow. During the periods dominated by the winter monsoon, the differences in the $\mathrm{CaCO}_{3}$ contents within and between the periods therefore revealed differences in the parent materials in the source areas and in the transport processes, with little chemical weathering occurring after the initial deposition. In contrast, in the periods dominated by the summer monsoon, precipitation increased, water accumulated in low-lying areas and formed rivers and lakes, and extensive chemical weathering occurred. The $\mathrm{CaCO}_{3}$ leached from sediment deposits in the surrounding high terrains would be transported into rivers and lakes by flowing water, resulting in enrichment of $\mathrm{CaCO}_{3}$ in the fluvial and lacustrine facies. For example, the relatively high $\mathrm{CaCO}_{3}$ content in $25 \mathrm{LS}$ was probably correlated with the development of lacustrine facies in MGS2.

The relationships between $\mathrm{Mz}$ and $\mathrm{CaCO}_{3}$ for the three main groups of facies (Fig. 5) in MGS2 further illustrate the differences among the three sedimentary facies. The $\mathrm{CaCO}_{3}$ content increased with increasing $\mathrm{Mz}$, but the lacustrine facies were clearly separated from the dune sand and fluvial facies, which mostly overlapped. Recent researches have shown that the physical (mechanical) fragmentation rate for particles with $M z<3.32$ in the flowing sands of desert areas increases during cold and dry periods with a windy environment, leading to deposits with relatively coarse particles and low calcium contents (Dong et al., 1983).

Within the $\mathrm{Mz}$ interval from 2.10 to 3.00 and for $\mathrm{CaCO}_{3}<1.0 \%$ (Fig. 4), most of the data points are for the dune sands, which suggests the dominance of a cold, dry, and windy sediment environment and dominance by the winter monsoon during those periods. The fluvial samples were mostly clustered in the $\mathrm{Mz}$ interval with $3.25>\mathrm{Mz}>2.50$ and $4.0 \%>\mathrm{CaCO}_{3}>$ $1.0 \%$. Because these samples overlap those for the dune sands, this suggests similar but somewhat warmer and wetter conditions. The samples from the lacustrine facies occur primarily at $\mathrm{Mz}>3.00$ and $\mathrm{CaCO}_{3}>4.0 \%$, and there are no dune sands in this part of the graph; this indicates weakening of the winter monsoon, which is the driving force for the accumulation of dune sands. Instead, the summer monsoon became dominant, indicating the occurrence of a warm and humid environment with weaker winds.

Many researchers (e.g. Liu et al., 2000; Li et al., 2004) have shown that the East Asian winter and summer monsoons had opposite effects on the climate and sedimentation environment in Northeast China during the Quaternary, but that they also interacted to serve as combined carriers of climatic signals. When the summer monsoon prevailed, winds originated in the southeast and traveled to the northwest, greatly weakening the winter monsoon and bringing much precipitation to the Salawusu River Valley and even into the $\mathrm{Mu}$ Us Desert. As a result of the warm and humid climate, the paleo-mobile dune sands became fixed, and fluvial and lacustrine facies developed.

The grain-size and $\mathrm{CaCO}_{3}$ data also correspond to the paleoecological evidence, such as the presence of fossil gastropods in some layers of MGS2 (Fig. 2). For example, the peak $\mathrm{CaCO}_{3}$ content in 25LS coincides with a lacustrine facies that contained fossils of Succinea erythrophana Ancey, Galba pervia (Martens), and Gyraulus sibiricus (Dunker), which are species that are still extant and inhabit humid areas with warm water, providing further evidence of a warm and humid climate. The fossil eggs of the vertebrate Struthiolithus anderssoni appeared in 20D and 24D, which are facies with a relatively coarse grain-size composition and low $\mathrm{CaCO}_{3}$ content, which indicates a cold and dry environment during those periods (Li et al., 2000).

The age range for MGS2 is close to that of MIS2 (from 23 to $10 \mathrm{ka} \mathrm{BP}$ ), and the time sequences for the variations in the East Asian winter and summer monsoons in MGS2 are similar to those recorded in MIS2. For example, layers 30D and 24D in the present study, 
which mainly formed under the influence of the winter monsoon, correspond to layers $\mathrm{H} 2$ and $\mathrm{H} 1$, which represent cold events in MIS2 (Bond et al., 1993); similarly, layers 24D, 22D, and 20D correspond to the cold Oldest Dryas, Older Dryas, and Younger Dryas (Dansgaard et al., 1993), respectively, and layers $23 \mathrm{FL}$ and $21 \mathrm{FL}$, which represent periods with a warm and humid climate, correspond to the warm and humid Bølling-Allerød periods (Dansgaard et al., 1993).

Our results show that MGS2 recorded dramatic climate variations during the Pleniglacial, indicated by low $\mathrm{CaCO}_{3}$ contents in many periods (with a low value nearing 0 in 20D) and extremely high $\mathrm{CaCO}_{3}$ contents in other periods (with a high value of $>15 \%$ in 25LS), which likely indicates periods when the climate quickly became cold or warm. These results are similar to the records of climate variation determined from China's Guliya ice cap (Yao and Shi, 1992).

\section{Conclusions}

Our analyses suggest that the coarse grain-size composition and low $\mathrm{CaCO}_{3}$ contents in the dune sands of MGS2 resulted from the dominance of a cold and dry environment that is typical of the East Asian winter monsoon, whereas the finer particles and higher $\mathrm{CaCO}_{3}$ contents in the overlying fluvial and lacustrine facies indicate a warm and humid environment that is typical of the East Asian summer monsoon. Thus, the alternations between peak and low values in the grain-size distribution and

\section{References}

An Z S. 2000. The history and variability of the East Asian paleomonsoon climate. Quaternary Science Reviews, 19(1-5): 171-187.

Bascomb C L. 1961. A calcimeter for routine use on soil samples. Chemistry and Industry, 14(4): 1826-1827.

Bond G, Heinrich H, Broecker W, et al. 1992. Evidence for massive discharges of icebergs into the North Atlantic Ocean during the last glacial period. Nature, 360: 245-248.

Bond G, Broecker W S, Johnson S, et al. 1993. Correlations between climate records from North Atlantic sediments and Greenland ice. Nature, 365: 143-147.

Bond G, Lotti R. 1995. Discharges of icebergs into Atlantic on millen-
$\mathrm{CaCO}_{3}$ contents represent a climate cycle that indicates the alternation between dominance by the East Asian winter and summer monsoons. Our results reveal 5.5 climate cycles in the sedimentary facies of MGS2. The age of MGS2 is in the range of approximately $12 \mathrm{ka}$ (from 23 to $11 \mathrm{ka} \mathrm{BP}$ ), and the MGS2 contains 11 sedimentary sequences, with an overall mean of $1.09 \mathrm{ka}$ per sequence. This suggests an overall pattern of millennium-scale climate fluctuations in the East Asian winter and summer monsoons during the Pleniglacial in the study area. Moreover, the actual duration of the period when a given facies accumulated ranged from 0.40 to 2.57 $\mathrm{ka}$, with a mean of $1.1 \mathrm{ka}$, suggesting that there was considerable variation during the period represented by MGS2. In addition, the millennium-scale Pleniglacial climate fluctuations created by alternations between dominance by the East Asian winter and summer monsoons reflected global climate changes, which were probably triggered by alterations in the North Atlantic thermohaline circulation (Ding et al., 1996).

\section{Acknowledgments}

This research was funded by the National Basic Research Program of China (2010CB833405, 2004CB720206), the National Natural Science Foundation of China (40772118, 49971009), Foundation of the State Key Laboratory of Loess and Quaternary Geology, Institute of Earth Environment, Chinese Academy of Sciences (SKLLQG0309), the Research Grants Council Grant of the Hong Kong Special Administrative Region (HKU7243/04H), and the Knowledge Innovation Project of Chinese Academy of Sciences (KZCX2-SW-118).

nial scales during the last glaciation. Science, 267: 1005-1010.

Broecker W S. 1994. Massive iceberg discharges as triggers for global climate change. Nature, 372: 421-424.

Dansgaard W, Johnsen S J, Clausen H B, et al. 1993. Evidence for general instability of past climate from a 250-kyr ice core record. Nature, 364: 218-220.

Dansgaard W, White J W C, Johnsen S J. 1989. The abrupt termination of the Younger Dryas climate events. Nature, 339: 532-534.

Ding Z L, Ren J Z, Liu T S, et al. 1996. Millennial-scale monsoon-desert climate irregular variations and the mechanism during the Late Pleistocene. Science in China: Series D, 26(5): 
385-391.

Dong G R, Li B S, Gao S Y. 1983. The case study of the vicissitude of Mu Us Sandy Land since the Late Pleistocene according to the Salawusu River strata. Journal of Desert Research, 3(2): 9-14.

Du S H, Li B S, David D Z. 2009. East Asian monsoons and the desert environment evolution recorded by $\mathrm{CaCO}_{3}$ in MGS5 segment during the Last Interglacial in China's Salawusu River Valley. Natural Science Process, 19: 1187-1193.

Folk P L, Ward W D. 1957. Brazos River bar: a study in the significance of grain size parameters. Journal of Sedimentary Petrology, 27(1): 3-26.

Grootes P M, Stuiver M, White J W C. 1993. Comparison of oxygen isotope records from the GLSP2 and GRIP Greenland ice cores. Nature, 366: 552-554.

Huang Y Z, Wang N A, He T H, et al. 2009. The desertification of the $\mathrm{Mu}$ Us Desert and its relationship with humans. Chinese Geographical Sciences, 29(2): 206-211.

Jin H L, Li M Q, Su Z Z. 2007. Sedimentary age of strata in the Salawusu River Basin and climatic changing. Acta Geologica Sinica, 81: 307-315.

Li B S, Zhang Z Z, Jin H L, et al. 2000. Palaeo-monsoon activities of Mu Us Desert, China since 150 ka B.P.- a study of the stratigraphic sequences of the Milanggouwan section, Salawusu River area. Palaeogeography, Palaeoclimatology, Palaeoecology, 162: 1-16.

Li B S, Zhang D D, Wen X H, et al. 2005. A multi-cycle climatic fluctuation record of the last interglacial period: typical stratigraphic section in the Salawusu River Valley on the Ordos Plateau, China. Acta Geologica Sinica, 79(3): 398-404.

Li B S, Wen X H, Qiu S F, et al. 2007. Phases of environmental evolution indicated by primary chemical elements and paleontological records in the Upper Pleistocene-Holocene series for the Salawusu River Valley, China. Acta Geologica Sinica, 81(4): 555-565.

Li H X, Li B S, Wen X H, et al. 2010. Primary oxides change in MGS2 in Salawusu River Valley and indicated climatic change. Journal of Desert Research, 30(4): 808-815.

Li S, Qiang M R, Li B S, et al. 2004. The climate dramatic variations on the northwest margin of East Asian monsoon area during the Last Pleniglacial. Quaternary Review, 50(1): 106-112.

Li Z Z, Lin Z Y, Chen X L, et al. 2010. The sand grain-size cycles and climate changes during the Late Holocene in Yili River Valley, Xinjiang. Chinese Geographical Sciences, 30(4): 613-619.
Liu C, Peng Z C, Kong X H, et al. 2011. The climate variations from the record of Xifeng loess section between the Last Glacial Maximum and Holocene. Chinese Geographical Sciences, 31(4): 508-512.

Liu T S, Shi Y F, Wang R L. 2000. Table of Chinese Quaternary stratigraphic correlation remarked with climate change. Quaternary Sciences, 20(2): 108-128.

Lu H Y, An Z S. 1997. Pretreatment methods influences on grain size measurement of Loess. Chinese Science Bulletin, 42: 2535-2538.

Luo C, Peng Z C, Yang D, et al. 2008. Lop Nur environment changes indicated by multi-geochemical elements during 32-9 kyr BP and its response to global climate change. Geochemistry, 37(2): 139148.

Shao T J, Zhao J B, Li A J, et al. 2010. The grain-size distribution pattern of typical tall sand hills in Badan Jaran Desert. Chinese Geographical Sciences, 30(5): 790-795.

Stuiver M, Reimer P J, Bard E, et al. 1998. Intcal98 radiocarbon age calibration 240,000-0 cal BP. Radiocarbon, 40(2): 1041-1083.

Sun J M, Ding Z L, Yuan B Y, et al. 1996. Stratigraphical Quaternary division of the Sala Wusu formation and the inferred sedimentary environment. Marine Ecology and Ecology, 16: 23-31.

Thompson L G, Mosley-Thompson T E, Davis M E, et al. 1995. Late glacial stage and Holocene tropical ice core records from Huascarán, Peru. Science, 269: 46-50.

Wang X Y, Zhang G S, Zhang A L, et al. 2005. The early-middle Holocene environment evolutions from the records of the lake sediments in the Chaohu Lake, China. Chinese Science Bulletin, 53: 132-138.

Wang Y J, Cheng H, Edwards R L, et al. 2001. A high-resolution absolute-dated Late Pleistocene monsoon record from Hulu Cave China. Science, 294: 2345-2348.

Xiao J L, Porter S C, An Z S, et al. 1995. Grain size of quartz as an indicator of winter monsoon strength on the Loess Plateau of Central China during the last 130,000 yr. Quaternary Research, 43: $22-29$.

Yao T D, Shi Y F. 1992. Climatic changes of Holocene reflected in the ice core from Dunde, Qilian Mountains. In: Shi Y F. The Climates and Environments of Holocene Megathermal in China. Beijing: China Ocean Press, 206-211.

Yuan B Y. 1978. Sedimentary environment and stratigraphical subdivision of Sjara Osso-Gol formation. Scientia Geologica Sinica, 3: 220-234. 